\title{
Mechanism on oscillating lifted flames in nonpremixed laminar coflow jets
}

\author{
Kyu Ho Van ${ }^{1}$, Jeong Park ${ }^{1}$, Sung Hwan Yoon ${ }^{2}$, Suk Ho Chung ${ }^{2}$, Min Suk Cha²* \\ ${ }^{1}$ Pukyong National University \\ Department of Mechanical Engineering \\ Busan 608-737, Republic of Korea \\ ${ }^{2}$ King Abdullah University of Science and Technology (KAUST) \\ Clean Combustion Research Center (CCRC), Physical Science and Engineering Division(PSE) \\ Thuwal 23955-6900, Saudi Arabia
}

\begin{abstract}
The oscillating lifted flame in a laminar nonpremixed nitrogen-diluted fuel jet is known to be a result of buoyancy, though the detailed physical mechanism of the initiation has not yet been properly addressed. We designed a systematic experiment to test the hypothesis that the oscillation is driven by competition between the positive buoyancy of flame and the negative buoyancy of a fuel stream heavier than the ambient air. The positive buoyancy was examined with various flame temperatures by changing fuel mole fraction, and the negative buoyancy was investigated with various fuel densities. The density of the coflow was also varied within a certain range by adding either helium or carbon dioxide to air, to study how it affected the positive and negative buoyancies at the same time. As a result, we found that the range of oscillation was well-correlated with the positive and the negative buoyancies; the former stabilized the oscillation while the latter triggered instability and became a source of the oscillation. Further measurements of the flow fields and $\mathrm{OH}$ radicals evidenced the important role of the negative buoyancy on the oscillation, detailing a periodic variation in the unburned flow velocity that affected the displacement of the flame.
\end{abstract}

Keywords: lifted flame, oscillation, positive buoyancy, negative buoyancy 


\section{Introduction}

Laminar lifted nonpremixed jet flames present a unique platform to research the effect of the mixture fraction gradient on the flame dynamics of edge flames [1]. Laminar lifted flames stabilize when the propagation speed of a flame edge is balanced by the upstream flow velocity, exhibiting the importance of the Schmidt number on stability [2-5]. One typical structure of a lifted flame edge in a nonpremixed fuel jet is the tribrachial flame, which consists of leading premixed flame wings with a continuously varying equivalence ratio (lean to rich) due to the mixture fraction gradient along the flame surface and a trailing diffusion flame originating from a stoichiometric location in the premixed flame.

The propagation speed of a flame edge is affected by mixture strength (the degree of dilution), mixture fraction gradient (caused by diffusion or local flow strain), flame curvature (flame stretch), and the Lewis number (Le). Meanwhile, the upstream velocity is influenced by the initial jet velocity, flame curvature (which causes a flow redirection), and buoyant forces that act on both the non-reacting part of the fluid as well as downstream from the flame. A lifted flame moves dynamically to find a new stable position whenever it faces perturbations or changes in the abovementioned factors, and may show an oscillating motion when the source(s) of the affecting factor(s) change periodically.

Experiments have found oscillating nonpremixed lifted flames travelling axially up and down in nitrogen-diluted propane jets [6, 7]. Won et al. [6] suggested that a buoyancy-driven instability triggered this oscillation, while Füri et al. [7] proposed a diffusive-thermal instability due to a large Le. Won et al. [8] validated the buoyancy-driven triggering mechanism for the oscillation via a microgravity experiment. It has been hypothesized that a periodic change in overall heat release, caused by a variation in the flame shape during one cycle of oscillation, results in a modification of the unburned upstream flow field, such that the continuously oscillating motion can be attributed to the periodic imbalance between the instantaneous propagation speed of the flame edge and the upstream velocity [9]. However, a parametric study has not been performed to clarify the initiating physical mechanism of the oscillation. 
In this study, motivated by recent work on the role of negative buoyancy in the unburned part of nonpremixed jet flames [10], we designed an experiment to provide a clear picture of the onset of oscillating lifted flames. Our present hypothesis is that the onset of the flame oscillation is related with competition between two counteracting forces in a system - a positive buoyancy that acts on the burned region, causing entrainment and, thus, increased upstream velocity, and a negative buoyancy that acts on the fuel stream to drag down the upstream velocity because the fuel is heavier than the ambient. To validate our hypothesis, we investigated the effect of the positive buoyancy on the onset at various flame temperatures, and the negative buoyancy was examined with various fuels and ambient densities. We established a criterion for the onset of oscillation and evaluated the detailed characteristics of the flame during the oscillation.

\section{Experiment}

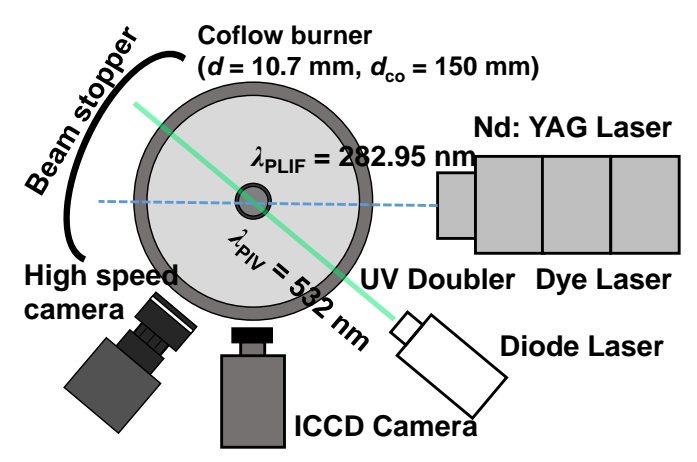

Fig. 1. Schematic of the experimental setup.

The experimental apparatus consisted of a coflow burner, a flow control system, and measurement setups (Fig. 1). The inner diameter $(d)$ of the fuel nozzle and the coflow section $\left(d_{\mathrm{co}}\right)$ were $10.7 \mathrm{~mm}$ and $150 \mathrm{~mm}$, respectively. The length of the nozzle was $800 \mathrm{~mm}$ so that the flow could fully develop inside in a laminar regime. A layer of glass beads at the bottom of the coflow section and a ceramic honeycomb near the exit of the nozzle were installed in order to ensure a uniform velocity 
profile at the exit. To avoid entraining the ambient air to the coflow gas, a cylinder (inner diameter: 16 $\mathrm{cm}$; length: $50 \mathrm{~cm}$ ) with three rectangular quartz windows for laser diagnostics was installed on top of the burner.

We selected propane diluted with nitrogen as the base fuel with an initial fuel mole fraction range of $0.120 \leq X_{\mathrm{F}} \leq 0.235$, similar to a previous study [6]. To further investigate the effect of fuel density on the oscillating lifted flame behavior, the binary fuel mixtures of propane/ethane and propane/n-butane were also tested to simulate lighter and heavier fuel densities, respectively (Table 1).

Table 1. Experimental conditions.

\begin{tabular}{ccccc}
\hline Fuel & $\begin{array}{c}\text { Fuel mole } \\
\text { fraction } \\
X_{\mathrm{F}}\end{array}$ & $\begin{array}{c}\text { Fuel-stream } \\
\text { density } \\
\rho_{\mathrm{f}}\left[\mathrm{kg} / \mathrm{m}^{3}\right]\end{array}$ & $\begin{array}{c}\text { Coflow gas } \\
\text { density } \\
\rho_{\mathrm{co}}\left[\mathrm{kg} / \mathrm{m}^{3}\right]\end{array}$ & $\begin{array}{c}T_{\mathrm{ad}}[\mathrm{K}]^{*} \\
(\mathrm{~min}-\mathrm{max})\end{array}$ \\
\hline & 0.120 & 1.22 & & $1820-1930$ \\
$\mathrm{C}_{3} \mathrm{H}_{8}$ & 0.135 & 1.23 & & $1850-1960$ \\
& 0.150 & 1.24 & & $1880-1990$ \\
& 0.235 & 1.30 & & $1970-2090$ \\
\hline $\mathrm{C}_{3} \mathrm{H}_{8} / \mathrm{C}_{2} \mathrm{H}_{6}$ & 0.157 & 1.20 & 1.07 & $1850-1960$ \\
$(1: 1)$ & 0.174 & 1.21 & $\left(\right.$ at $\left.X_{\mathrm{He}}=0.1\right)$ & $1880-1990$ \\
& 0.268 & 1.25 & $\left(\right.$ at $\left.\mathrm{X}_{\mathrm{CO} 2}=0.1\right)$ & $1970-2090$ \\
\hline & 0.112 & 1.24 & & $1820-1930$ \\
$\mathrm{C}_{3} \mathrm{H}_{8} / \mathrm{n}-\mathrm{C}_{4} \mathrm{H}_{10}$ & 0.126 & 1.25 & & $1850-1960$ \\
$(3: 1)$ & 0.141 & 1.26 & & $1880-1990$ \\
& 0.218 & 1.32 & & $1970-2090$ \\
\hline *Calculated adiabatic flame temperature with $\mathrm{X}_{\mathrm{CO} 2}=0.1$ (min) and $\mathrm{X}_{\mathrm{He}}=0.1$ (max).
\end{tabular}

${ }^{*}$ Calculated adiabatic flame temperature with $\mathrm{X}_{\mathrm{CO} 2}=0.1(\mathrm{~min})$ and $\mathrm{X}_{\mathrm{He}}=0.1(\mathrm{max})$.

To vary the density of the coflow gas, a mixture of nitrogen and helium (or nitrogen and carbon dioxide) was added to the air stream. The volume fraction of the mixture added to the coflow gas was fixed at 0.1 ; e.g., $X_{i}+X_{\mathrm{N} 2}=0.1\left(i=\mathrm{He}\right.$ or $\left.\mathrm{CO}_{2}\right)$ and $X_{\mathrm{air}}=0.9$. Also, $X_{i}$ and $X_{\mathrm{N} 2}$ were systematically varied between $\left(X_{i}=0, X_{\mathrm{N} 2}=0.1\right)$ and $\left(X_{i}=0.1, X_{\mathrm{N} 2}=0\right)$. Thus, the density of the coflow gas $\left(\rho_{\mathrm{co}}\right)$ was varied from $1.07\left(X_{\mathrm{He}}=0.1\right)$ to $1.23\left(X_{\mathrm{CO} 2}=0.1\right) \mathrm{kg} / \mathrm{m}^{3}$. Throughout the experiment, the mole fraction of oxygen was fixed at 0.189 , and the coflow velocity was maintained at $u_{\mathrm{co}}=8.46 \mathrm{~cm} / \mathrm{s}$. Mass flow controllers (Brooks Instrument, 0260 Series) maintained the flow rate of each gas. The experimental 
conditions used to map out the oscillating behavior in terms of coflow density, fuel-stream density ( $\left.\rho_{\mathrm{f}}\right)$, and fuel mole fraction are listed in Table 1. The adiabatic flame temperature in the table were calculated using Chemkin Pro package [11] with USC Mech II [12], and the domains of $X_{\mathrm{F}}$ were predetermined to have a similar range of adiabatic flame temperatures to the propane flames.

For flow visualization and particle image velocimetry (PIV), a continuous-wave diode laser (Coherent, Genesis 532-2000 S OPSL, 532 nm), a high-speed camera (Photron, FASTCAM-ultimaAPX), and oil mist generators using Smoke Oil 180 were used. When visualizing the flow field highlighting a boundary between the fuel stream and the coflow, oil mist was added into the coflow stream only; for the PIV analysis, the oil mist was supplied through both the fuel and the coflow streams. The frame rate of the high-speed camera was $1000 \mathrm{fps}$, and the PIV analysis was performed using a Matlab code (PIVlab) with two adjacent images with a $1 \mathrm{~ms}$ time interval [13]. The OH radical distribution was visualized using the planar laser-induced fluorescence (PLIF) technique with a set of Nd:YAG (Continuum, Powerlite 9010), a tunable dye laser (Continuum, ND6000), and a frequency doubler (Continuum, UVT-3). The excitation line at the $\mathrm{Q}_{1}(6)$ transition $\mathrm{A}^{2} \Sigma^{+}-\mathrm{X}^{2} \Pi(1,0)$ band of $\mathrm{OH}$ radical was set to $282.95 \mathrm{~nm}$, and the fluorescence signal was captured by an intensified chargecoupled device (ICCD) camera (Princeton Instruments, PI-MAX2-1024i) with a UV-Micro-APO 105 $\mathrm{mm} \mathrm{f} / 4$ lens and a set of UG-11 and WG-305 filters.

\section{Results and discussion}

\subsection{Overall features of the onset of flame oscillation}

We chose a nitrogen-diluted propane $\left(X_{\mathrm{F}}=0.235\right)$ and a coflow composition of $X_{\mathrm{N} 2}=0.1$ and $X_{\text {air }}=0.9$ as our example to highlight oscillating lifted flames in the present study. We investigated the flame behavior as the fuel jet velocity increased; the resulting liftoff heights are illustrated in Fig. 2. Similar to the previously report [6], the stationary lifted flame (Fig. 2a) started to oscillate at $u_{\mathrm{o}} \sim 2$ $\mathrm{cm} / \mathrm{s}$, then stabilized again at $u_{\mathrm{o}} \sim 11 \mathrm{~cm} / \mathrm{s}$ (Fig. $2 \mathrm{~d}$ ). For a given jet velocity of $2<u_{\mathrm{o}}<11 \mathrm{~cm} / \mathrm{s}$, the 
upper branch in the graph indicates the maximum height of the flame base from the nozzle rim during oscillation (Fig. 2b) and the lower branch shows the minimum (Fig. 2c); the greatest oscillation was observed at $u_{\mathrm{o}}=7 \mathrm{~cm} / \mathrm{s}$. The limited range of flame oscillation in terms of $u_{\mathrm{o}}$ was explained previously through numerical simulations by the phase delays among the reaction rate, buoyancy, and convection [9]. Again, it has been substantiated through a microgravity experiment and numerical simulation that such oscillating flames are caused by a buoyancy-driven instability $[6,8,9]$.

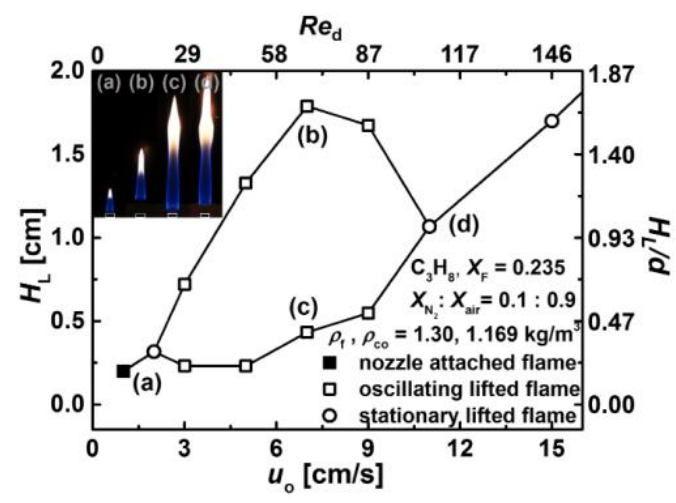

Fig. 2. Typical flame behavior in terms of the jet velocity and the flame base position at $X_{\mathrm{F}}=0.235 ; X_{\mathrm{N} 2}$ $=0.1$ and $X_{\text {air }}=0.9$ in the coflow with $u_{\mathrm{co}}=8.46 \mathrm{~cm} / \mathrm{s}$.

However, two buoyancy forces act on a laminar lifted nonpremixed jet flame system: a positive buoyancy due to the difference between the densities of burnt and unburnt gases, and a negative buoyancy caused by the difference between the heavier, cold fuel jet and the coflow gas stream. Therefore, we investigated how the critical condition, i.e., where the flame oscillation starts (Fig. 2a), is affected by the two opposing buoyancies. We found that the mole fraction of the fuel in the jet stream influenced both the flame temperature and the density at the same time, and that diluents in the coflow varied both the coflow density and the flame temperature. For a given fuel mole fraction, we varied the coflow density in a domain of $1.07 \leq \rho_{\mathrm{co}} \leq 1.23 \mathrm{~kg} / \mathrm{m}^{3}$ and determined the range of the flame oscillation in terms of $u_{\mathrm{o}}$ and $\rho_{\mathrm{co}}$. 


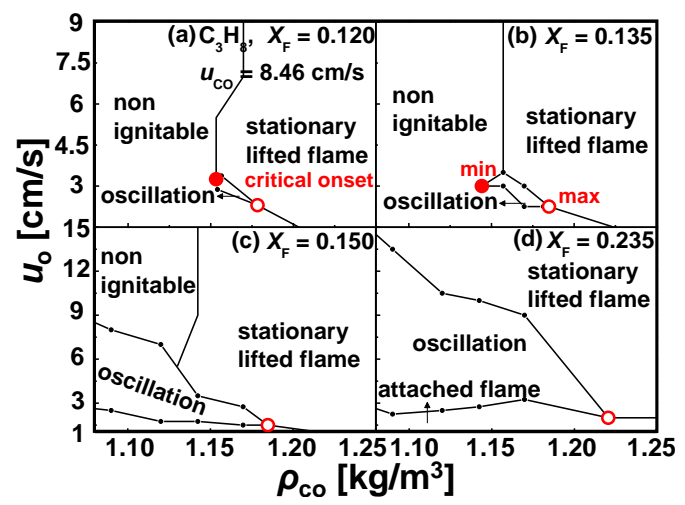

Fig. 3. Domains of the flame oscillation in terms of coflow density and jet velocity for propane at $u_{\mathrm{co}}=$ $8.46 \mathrm{~cm} / \mathrm{s}:$ a) $X_{F}=0.120\left(\rho=1.22 \mathrm{~kg} / \mathrm{m}^{3}\right)$, b) $0.135\left(1.23 \mathrm{~kg} / \mathrm{m}^{3}\right)$, c) $0.150\left(1.24 \mathrm{~kg} / \mathrm{m}^{3}\right)$, and d) 0.235 $\left(1.30 \mathrm{~kg} / \mathrm{m}^{3}\right)$.

Figure 3 illustrates the ranges of flame oscillation as well as some flame behaviors beyond these ranges. In general, as the fuel mole fraction increased, the range of the oscillation in terms of $u_{\mathrm{o}}$ and $\rho_{\mathrm{co}}$ was significantly extended. The maximum critical coflow densities (open circles in Fig. 3), below which oscillation occurs, also increased with increasing $X_{\mathrm{F}}$; e.g., $0.178,0.181,1.185$, and 1.221 $\mathrm{kg} / \mathrm{m}^{3}$ for $X_{\mathrm{F}}=0.120,0.135,0.150$, and 0.235 , respectively. On the other hand, the minimum critical coflow densities (closed circles in Fig. 3) in the tested domain of the coflow density occur at $X_{\mathrm{F}}=$ 0.120 and 0.135 , indicating that the oscillation can be found only in a limited, bounded range of the coflow density. We noted that the minimum intervals of $u_{\mathrm{o}}$ and $\rho_{\mathrm{co}}$ adopted in the experiment were $0.25 \mathrm{~cm} / \mathrm{s}$ and $0.003 \mathrm{~kg} / \mathrm{m}^{3}$, respectively, and repeated measurements confirmed that the measured critical points were bounded in $\pm 0.25 \mathrm{~cm} / \mathrm{s}$ and $\pm 0.003 \mathrm{~kg} / \mathrm{m}^{3}$.

For the jet velocities lower than the minimum $u_{\mathrm{o}}$ for an oscillation at a given $\rho_{\mathrm{co}}$, nozzleattached flames could be found at $X_{\mathrm{F}}=0.235$ regardless of the coflow density, whereas stationary lifted flames were observed for jet velocities higher than the maximum $u_{\mathrm{o}}$. However, at $X_{\mathrm{F}} \leq 0.150$, the flame was extinguished for the jet velocities below the minimum $u_{\mathrm{o}}$ for the oscillation. At $X_{\mathrm{F}}=0.120$ and 0.135 in particular, no stable flames were found at the coflow densities lower than $\rho_{\mathrm{co}}=1.144$ and $1.153 \mathrm{~kg} / \mathrm{m}^{3}$, respectively, indicating that these are critical conditions for flame extinction at the same 
time.

Speculating that the critical coflow density for each fuel mole fraction has important implications for the flame oscillation, we further investigated these critical conditions using two different fuel mixtures, as shown in Table 1. A propane and ethane mixture was chosen to simulate a fuel with a lower density than pure propane, while a propane and n-butane mixture represented a fuel heavier than propane. Thus, we could examine the effects of the aforementioned opposing buoyancies on the flame oscillation. The critical onset conditions are shown in Fig. 4 in terms of $X_{\mathrm{F}}$ and $\rho_{\mathrm{co}}$.

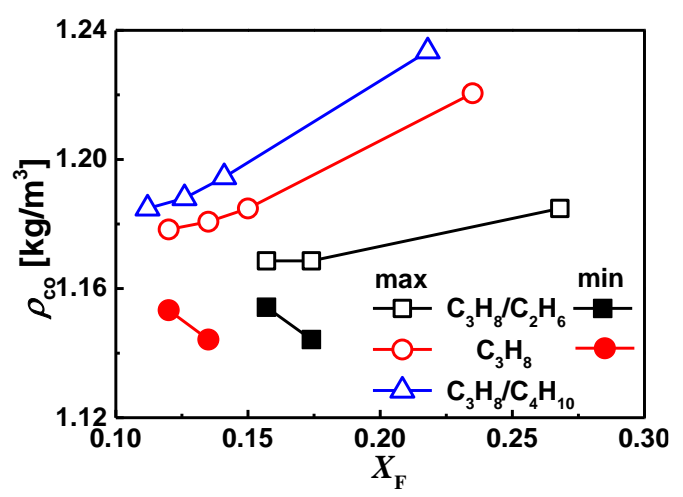

Fig. 4. Critical onset conditions for oscillation: open and closed symbols for the maximum and minimum coflow densities, respectively, at a given $X_{F}$.

For all tested fuel mixtures, the flame oscillation occurred in a wider range of coflow densities as the fuel mole fraction increased, indicating an increase in the maximum onset coflow density and a decrease in the minimum onset density. We also found that the maximum coflow density for the flame oscillation became higher at a given $X_{\mathrm{F}}$ with the heavier fuel density. The fuel mole fraction changed the density of the fuel jet and the flame temperature at the same time; the coflow density affected the buoyant forces acting on the burned gas and the cold fuel jet, as well as the flame temperature. 


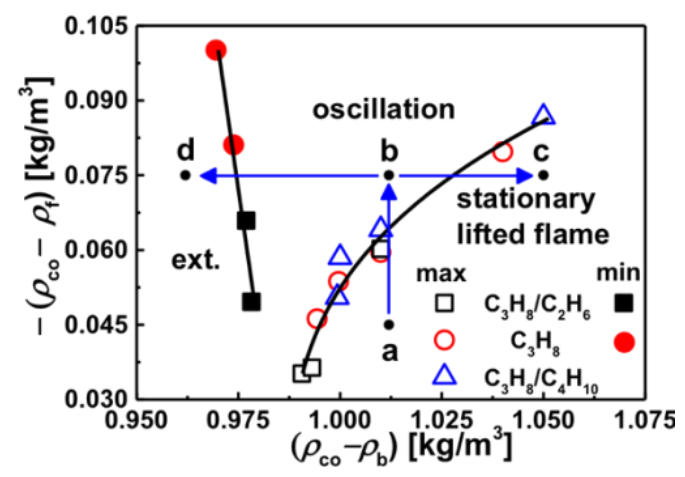

Fig. 5. Relations among critical onset conditions in terms of density differences; $\rho_{c o}-\rho_{0}$ representing positive buoyancy and $\rho_{\mathrm{co}}-\rho_{\mathrm{r}}$ negative buoyancy on the fuel stream.

We can obtain well correlated result of the critical conditions for all experimental conditions (Fig. 5), as we introduced two parameters: the difference in density between the coflow and the burned gas $\left(\rho_{\mathrm{co}}-\rho_{\mathrm{b}}\right)$, representing the buoyancy due to the flame; and the difference in density between the coflow and the fuel jet $\left(\rho_{\mathrm{co}}-\rho_{\mathrm{f}}\right)$, representing the buoyancy acting on the cold fuel jet. We note that $\left(\rho_{\mathrm{co}}-\rho_{\mathrm{f}}\right)<0$ results in a negative buoyancy on the cold fuel jet, indicating the downward direction of force, while $\left(\rho_{\mathrm{co}}-\rho_{\mathrm{b}}\right)>0$ results in a positive buoyancy acts upwardly on the burnt gas. Because the volumes of interest for the buoyant forces were time-dependent during the oscillation, we could not use the explicit forms of the buoyant forces in this analysis. The burned densities were obtained as a result of the calculation done in Table 1.

As shown in Fig. 5, the stable lifted flames, having similar adiabatic flame temperatures among the various fuel mixtures with different fuel mole fractions, became unstable (i.e., began to oscillate up and down) as the negative buoyancy, $\sim\left(\rho_{\mathrm{co}}-\rho_{\mathrm{f}}\right)$, increased ( $\rightarrow \mathrm{b}$ in Fig. 5), whereas an increase in the positive buoyancy, $\sim\left(\rho_{\mathrm{co}}-\rho_{\mathrm{b}}\right)$, stabilized the flame oscillation $(\mathrm{b} \rightarrow \mathrm{c})$. However, a further decrease in the positive buoyancy extinguished the flame $(b \rightarrow d)$.

Therefore, we concluded that the flame oscillation could be attributed to the effects of the two competitive forces acting on the flow field. The positive buoyancy of the burnt gas stabilized the cold flow region below the lifted flame base, promoting ambient entrainment. The negative buoyancy of 
the fuel jet pulled the cold flow region down, leading to an unstable flow. In addition, the jet momentum seemed to affect the range of the oscillation, as shown in Fig. 3. However, since the fuel jet velocities at the onset conditions were $\sim 2$ and $\sim 3.5 \mathrm{~cm} / \mathrm{s}$ at the maximum and minimum $\rho_{\mathrm{co}}$, respectively, the effect of the jet momentum on each critical condition may be neutral.

\subsection{Characteristics of flow fields and flames in oscillation}

To investigate the effect of the negative buoyancy on the fuel stream due to $\rho_{\mathrm{co}}-\rho_{\mathrm{f}}<0$, we visualized cold flow fields at various coflow densities with a nitrogen-diluted propane jet at $X_{\mathrm{F}}=0.150$ and $u_{\mathrm{o}}=3 \mathrm{~cm} / \mathrm{s}$. The oil mist was seeded into the fuel stream. The resulting vertical tomographic images are shown in Fig. 6 for $\rho_{\mathrm{co}}=1.071$ (a), 1.120 (b), 1.169 (c), and 1.201 (d) kg/m $\mathrm{m}^{3}$. A stagnation height of the fuel core $(L)$ formed as the central part of fuel jet lost momentum, then flowed radially outwards. Since the coflow velocity $(8.46 \mathrm{~cm} / \mathrm{s})$ was higher than that of the fuel jet, the fuels were carried downstream by the coflow momentum. As the coflow density increased, the spreading angle of the fuel mixture $(\alpha)$ decreased and $L$ increased at the jet axis. This was caused by the reduced difference in density as the coflow density increased, which resulted in a decreased negative buoyancy. This affected the mixing behavior, characterized by an overall equivalence ratio along the jet axis and a local mixture fraction along the radial direction. However, when the cold flow field was under the influence of a flame, the effect of the flame's positive buoyancy may play a greater role in the mixing behavior and flow field variation. 


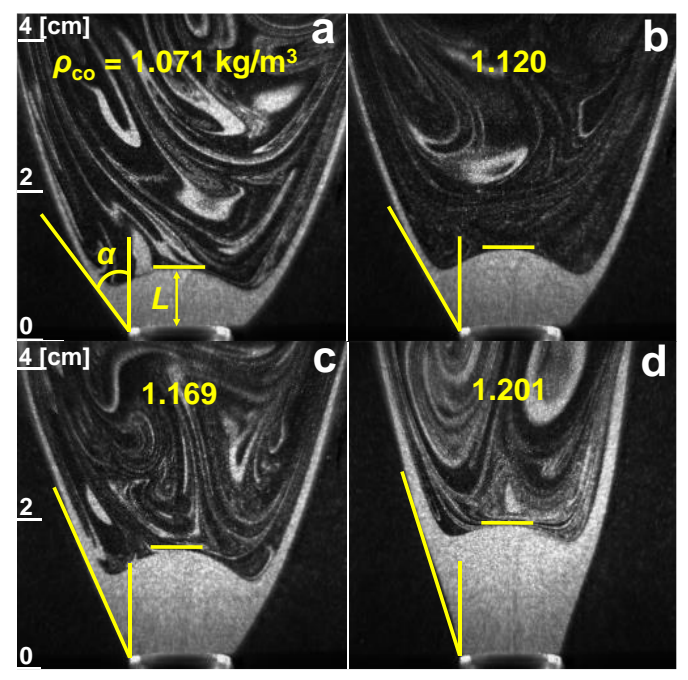

Fig. 6. Effect of coflow density on cold flow fields with oil mist seeded into the fuel stream at $X_{F}=0.150$ $\left(\rho=1.23 \mathrm{~kg} / \mathrm{m}^{3}\right)$ and $u_{\mathrm{o}}=3 \mathrm{~cm} / \mathrm{s}:$ a) $\left.\left.\rho_{\mathrm{co}}=1.071, \mathrm{~b}\right) 1.120, \mathrm{c}\right) 1.169$, and d) $1.201 \mathrm{~kg} / \mathrm{m}^{3}$, at $u_{\mathrm{co}}=8.46$ $\mathrm{cm} / \mathrm{s}$.

Figures 7 and 8 illustrate various flow and flame characteristics of the propane flame $\left(X_{\mathrm{F}}=\right.$ $0.150)$ during a cycle of oscillation for $\rho_{\mathrm{co}}=1.169\left(X_{\mathrm{N} 2}=0.1\right)$ and $\rho_{\mathrm{co}}=1.071 \mathrm{~kg} / \mathrm{cm}^{3}\left(X_{\mathrm{He}}=0.1\right)$, respectively. A Mie scattering image of the cold flow behavior was captured by seeding oil mist in the coflow section; the iso-thermal contour for the evaporation of the oil mist $\left(\sim 230^{\circ} \mathrm{C}\right)$ was also visualized over the flame zone. The PIV results were obtained by seeding mist in both the fuel and the coflow streams. The size of the flame was estimated from the PLIF image of the $\mathrm{OH}$ radicals; thus, the relative magnitude of the positive buoyancy due to the flame could be compared among the instantaneous flames during the cycle. Although the size and location of the flame were slightly affected by the supplied oil mist during the PIV measurement, the overall dynamic motion of the flame was reasonably maintained. For the oscillation in Fig. 7 as an example, due to the oil mist, the oscillation frequency was reduced from $2.028 \mathrm{~Hz}$ to $1.71 \mathrm{~Hz}$, the range of the flame base height was reduced to $2.06-3.48$ $\mathrm{cm}$ from $1.71-3.85 \mathrm{~cm}$. 


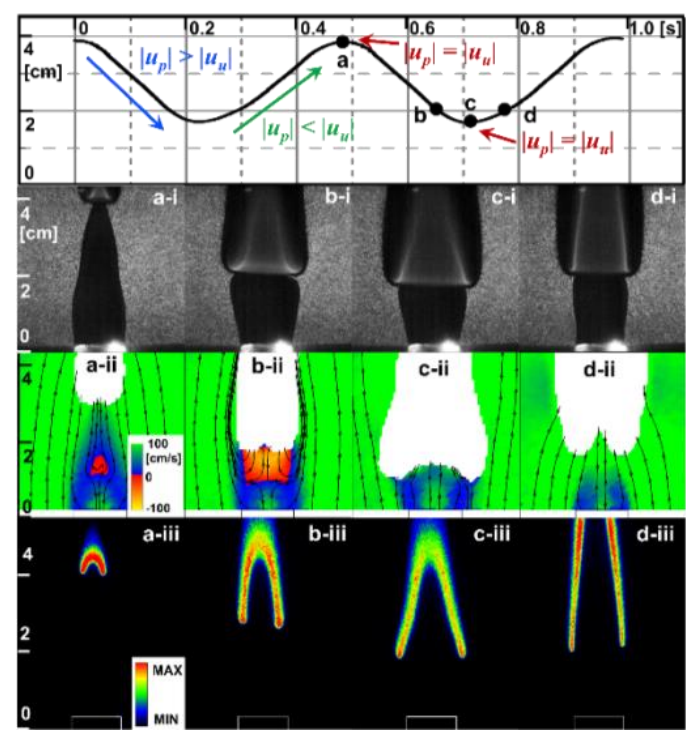

Fig. 7. Characteristics of the oscillating lifted flame for $X_{\mathrm{F}}=0.150\left(\rho_{\mathrm{f}}=1.23 \mathrm{~kg} / \mathrm{m}^{3}\right), u_{\mathrm{o}}=3 \mathrm{~cm} / \mathrm{s}, u_{\mathrm{co}}=$ $8.46 \mathrm{~cm} / \mathrm{s}$, and $\rho_{\mathrm{co}}=1.169 \mathrm{~kg} / \mathrm{m}^{3}$; history of flame-base height (top row), Mie-scattering images (i), PIV results (ii), and OH PLIF images (iii). The oscillation frequency was $2.028 \mathrm{~Hz}$.

In the top row of Fig. 7, a quasi-sinusoidal cyclic motion of the flame base can be observed for $\rho_{\mathrm{co}}=1.169 \mathrm{~kg} / \mathrm{m}^{3}$. Four distinctive flames observed during the oscillation are shown: flames at the maximum (a) and minimum (c) heights from the nozzle, and two flames at the same height but moving in opposite directions - approaching the nozzle (b) and moving away from the nozzle (d). Supplementary movie 1 shows comprehensive, high-speed images of the oscillating flame.

When the flame is at its maximum height, the fuel-stream column, which is represented by a dark zone at the center of Fig. 7a-i, becomes thinner from the nozzle to the flame base. Because the size of the $\mathrm{OH}$ zone shows the smallest at this moment during the cycle (Fig. 7a-iii), the minimal effect of the flame buoyancy on the flow field was expected, and the air entrainment due to the positive buoyancy between the nozzle and the flame base should also be minimized. In addition, the negative buoyancy also acts on this cold flow region by pulling the fuel stream down toward the nozzle. As a result, the low velocity region can be found indicated by a small recirculating zone at the center around $12 \mathrm{~mm}$ above the nozzle (Fig. 7a-ii).

Because the local dynamic motion of a flame is determined by flame propagation $\left(u_{\mathrm{p}}\right)$ speed and local flow velocity $\left(u_{\mathrm{u}}\right)$, the flame moved toward the nozzle (Fig. $7 \mathrm{~b}$ ) as a result of the flame 
displacement indicated by the displacement speed $\left(u_{\mathrm{d}}=u_{\mathrm{p}}+u_{\mathrm{u}},\left|u_{\mathrm{p}}\right|>\left|u_{\mathrm{u}}\right|\right)$. The gradually increasing flame surface (Fig. 7b-iii) imposed a thermal-expansion effect on the upstream, such that the downward flame movement pushed the unburned mixture ahead of the flame base, thereby reducing the incoming upstream velocity (Fig. 7b-ii). This modification of the cold flow was also evidenced by the swollen fuel-stream column near the flame base (Fig. 7b-i). The stagnant flow pattern was also found in the cold flow region above the nozzle, due to the downwash flow motion from the flame base.

The fact that the flame showed minimum position indicates that an inversion of velocity magnitude $\left(\left|u_{\mathrm{p}}\right|<\left|u_{\mathrm{u}}\right|\right)$ occurred after this minimum. Then, an instantaneous balance between the propagation speed of the flame edge and the local upstream velocity $\left(\left|u_{\mathrm{p}}\right|=\left|u_{\mathrm{u}}\right|\right)$ was satisfied at the minimum (Fig. 7c). We attribute the augmented positive buoyancy from the increased flame area (Fig. 7c-iii) to the rebalancing caused by increasing the entrainment velocity (Fig. 7c-ii). Thus, after increasing the entrainment velocity, a high velocity region under the flame base was identified (Fig. 7d-ii), such that this greater velocity of the upstream than the flame propagation will continuously push the flame base away from the nozzle until the flame shrinks again at its maximum location (Fig. 7aiii). Therefore, the oscillation is a result of the competition between entrainment due to the positive buoyancy and the cold flow being dragged down due to the negative buoyancy.

Because the negative buoyancy of the fuel stream is an important factor in the flame oscillation, as shown in Figs. 5 and 7, the flame showed an interesting behavior under the effect of a magnified negative buoyancy, i.e., when the flame was exposed to the lighter coflow density at $1.07 \mathrm{~kg} / \mathrm{m}^{3}$, as shown in Fig. 8. First of all, the flame trajectory during the oscillation cycle changed from the simple quasi-sinusoidal motion at $\rho_{\mathrm{co}}=1.17 \mathrm{~kg} / \mathrm{m}^{3}$ into a W-shape at $1.07 \mathrm{~kg} / \mathrm{m}^{3}$ (Supplementary movie 2). This is attributed to the cold flow pattern - a crown shape - shown in Fig. 8b-i. 


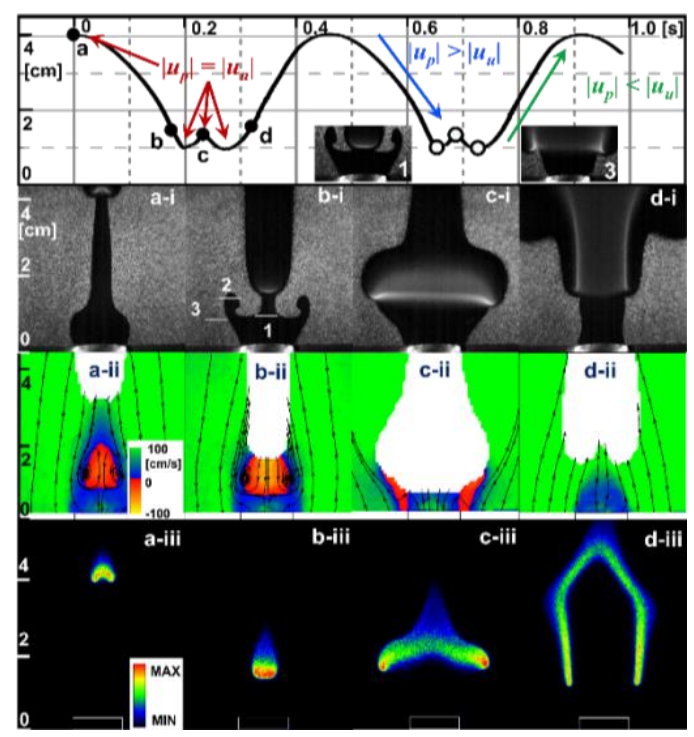

Fig. 8. Characteristics of the oscillating lifted flame for $X_{\mathrm{F}}=0.150\left(\rho_{\mathrm{f}}=1.23 \mathrm{~kg} / \mathrm{m}^{3}\right), u_{\mathrm{o}}=3 \mathrm{~cm} / \mathrm{s}, u_{\mathrm{co}}=$ $8.46 \mathrm{~cm} / \mathrm{s}$, and $\rho_{\mathrm{co}}=1.071 \mathrm{~kg} / \mathrm{m}^{3}$; history of the flame base height (top row), Mie-scattering images (i), PIV results (ii), and OH PLIF images (iii). The oscillation frequency was $2.030 \mathrm{~Hz}$.

The cold flow near the nozzle was strongly affected by the augmented negative buoyancy, showing a radially swollen volume of the fuel stream, as the effect of the positive buoyancy was minimized by the flame's minimal size at its maximum position (Fig. 8a-i). Such an augmented effect of the negative buoyancy was also evidenced in the flow field, which showed a recirculating, toroidalshaped roll-up vortex at the center of the fuel stream (Fig. 8a-ii). As the flame approached the nozzle (Fig. 8b-i), the cold flow near the nozzle continued to evolve as a result of the growing toroidal vortex into a shape similar to that in Fig. 6, which led to a temporary crown-shaped fuel stream. The first minimum position of the propagating flame was near the end of the thin fuel column, indicated by " 1 " in Fig. 8b-i; the inset 1 shows the flame. The flame expanded radially, following the contour of the flammable mixture over the central region of the roll-up vortex, until it moved over the peak of the crown-shaped fuel stream (the position is "2" in Fig. 8b-i, and Fig. 8c-i corresponds to the flame). Then, this flame edge propagated further downward until the propagation speed balanced with the local flow velocity, forming the second minimum position ("3" in Fig. 8b-i; see the inset).

The sudden increase in the flame area due to the radial expansion of the flame (Figs. 8c-iii and 8d-iii) created a huge positive buoyancy that increased the entrainment velocity under the flame base (Fig. 8d-ii). Again, this higher upstream velocity pushed the flame away from the nozzle until the 
positive buoyancy was weakened due to the reduced flame size at the maximum position (Fig. 8a-iii). The flame in the downward propagation, which had a convex shape toward the upstream unlike a typical tribrachial flame, seemed to be a result of the overall fuel-lean condition, because there was no trailing diffusion flame based on the $\mathrm{OH}$ distribution in Fig. 8b-iii. We attribute the enhanced transportation of the fuel towards the radial direction near the nozzle to the lean mixture in the thin, central fuel stream, as in Fig. 8a-i. Therefore, once again, we conclude that the flame oscillation was due to the imbalance between the flame propagation velocity and the local upstream velocity, and the role of negative buoyancy was essential to the flame oscillation because it reduced the cold flow velocity when the flame was far from the nozzle.

\section{Conclusions}

We investigated oscillating lifted flames in laminar nitrogen-diluted fuel jets to highlight the role of negative buoyancy on the onset and sustaining mechanisms of the flame oscillation. As the result of systematic experiments with various fuel and coflow densities, we concluded that the negative buoyancy of the fuel stream, due to the fuel being heavier than the coflow, was the key driver initiating and perpetuating the oscillation. The oscillation was a result of the competition between the positive buoyancy of the flame and the negative buoyancy of the fuel stream; the former stabilized the lifted flame and the latter disturbed the lifted flame, thus, leading to the oscillation via the counter-directional force of the negative buoyancy against the positive buoyancy.

More detailed characterizations (high-speed imaging, PIV, and OH PLIF) of the flames and flow fields during the oscillation evidenced instantaneous and localized effects of the positive and negative buoyancies. When the effect of positive buoyancy was minimized due to the minimal flame at the top of the oscillation, the negative buoyancy pulled the unburned flow back down, resulting in a flame displacement toward the nozzle. As the flame approached the nozzle, the effect of the positive buoyancy grew due to the flame's maximal size at the bottom of the oscillation, thus increasing the 
entrainment velocity and pushing the flame away from the nozzle.

\section{Acknowledgement}

The research reported in this publication was supported by funding from King Abdullah University of Science and Technology (KAUST) under award number BAS/1/1384-01-01. KHV and JP were supported by the project of Development of the Technology of Energy from KETEP in 20172018.

\section{References}

[1] S.H. Chung, Proc. Combust. Inst. 31 (2007) 877-892.

[2] S.H. Chung, B.J. Lee, Combust. Flame 86 (1991) 62-75.

[3] B.J. Lee, S.H. Chung, Combust. Flame 109 (1997) 163-182.

[4] T. Pressing, P. Terhoeven, N. Peters, Combust. Flame 115 (1998) 335-353.

[5] G.R. Ruetsch, L. Vervisch, A. Linan, Phys. Fluid 7 (1995) 1447-1454.

[6] S.H. Won, S.H. Chung, M.S. Cha, B.J. Lee, Proc. Combust. Inst. 28 (2000) 2093-2099.

[7] M. Füri, P. Papas, A. Monkewitz, Proc. Combust. Inst. 28 (2000) 831-838.

[8] S.H. Won, J. Kim, M.K. Shin, S.H. Chung, O. Fujita, T. Mori, J. H. Choi, K. Ito, Proc. Combust. Inst. 29 (2002) 37-44.

[9] J. Kim, S.H. Won, M.K. Shin, S.H. Chung, Proc. Combust. Inst. 29 (2002) 1589-1595.

[10] Y. Xiong, M. S. Cha, S. H. Chung, Proc. Combust. Inst. 35 (2015) 873-880.

[11] CHEMKIN-PRO package, Reaction Design, 6440 Lusk Boulevard, Suite D-205

San Diego, CA 92121. <http://www.reactiondesign.com>.

[12] H. Wang, X. You, A. V. Joshi, S. G. Davis, A. Laskin, F. Egolfopoulos, C. K. Law, available at http://ignis.usc.edu/USC_Mech_II.htm.

[13] W. Thielicke, E. J. Stamhuis, Journal of Open Research Software, 2 (1) (2014) p.e30, available at 
http://doi.org/10.5334/jors.bl. 